\title{
EGGS AND OVIPOSITION IN CERTAIN SPECIES OF MANSONIA
}

\author{
(Diptera; Culicida)
}

\section{By HARRISON G. DYAR AND FREDERICK KNAB}

The writers, in 1910 , briefly reviewed what was then known concerning the developmental stages in the genus Mansonia. ${ }^{1}$ Somewhat fuller data appear in a later work ${ }^{2}$ however, as far as the eggs are concerned, no new data have been made available within the last eight years. The eggs of but three American species, fasciolatus Arrib., arribalzage Theob., and perturbans Walk., have been made known, the first two by Goeldi, ${ }^{3}$ the last by several North American writers. ${ }^{4}$ In these forms the eggs do not differ greatly in shape, arrangement, and manner of disposal from eggs of typical Culex. They are subcylindrical, slightly tapered toward one end and rounded at both extremities. They are placed upright, in contact along their sides and with the broader end downward, thus conditioning the convex lower surface of the egg-boat. These eggboats float upon the surface of the water, one end usually resting against an aquatic plant.

There is some difference in the arrangement of the eggs in the three species. In Mansonia perturbans they form the usual roughly elliptical boat-shaped mass. In $M$. fasciolatus and $M$. arribalzagce the eggs, while placed upright and in contact as in $M$. perturbans, are arranged in a long double row consisting of about 120 eggs in all; this long band is gently convex on its lower surface, in consequence of the slight upward taper of the eggs.

The eggs of Mansonia titillans, the type of the genus, have

${ }^{1}$ The genus Mansonia. Entom. News, xxi, 1910, 259-264.

'Howard, Dyar and Knab. The Mosquitoes of North and Central America and the West Indies, iii, 1915, p. 503 et seq.

${ }^{8}$ Os Mosquitos no Pará. Boll. Mus. Paraense, 1902, p. 27, and Mem. Mus. Goeldi, iv, 1905, p. 106, pl. G.

${ }^{1}$ Dyar and Currie. Proc. Ent. Soc. Wash., vi, 1904, 218-219. Smith, John B., Entom. News, xix, 1908, 22. 
until now remained unknown. ${ }^{1}$ It may be recalled that Prof. Harold W. B. Moore, of British Guiana, discovered the larvæ of this species, which live attached to the roots of the peculiar floating aquatic plant, Pistia. The adult titillans shows much specialization. This, together with the fact that Professor Moore, a most able observer, in a locality where the species abounded failed to find eggs in situations where they were to be expected, led to the conclusion that the eggs are disposed of in an unusual manner. Such has now proved to be the case.

Professor Moore at our solicitation continued the quest with most remarkable results. He has most liberally placed at our disposal his notes and the accompanying material. His first announcement to us, under date of January 2, 1915, was as follows :

"You will be glad to know I discovered the eggs of Mansonia titillans on the 21 st of last month. I have also obtained them from a confined female. She sucked my hand at 4 p. m. on the $23 \mathrm{~d}$ December and was kind enough to oviposit on the night of the 28th. These, as well as clusters found in nature, I shall send forward to you. The eggs are certainly unique and are placed on the under surface of the leaves of Pistia. They are deposited in a mass, generally between ribs of the leaves."

Details concerning the eggs came in a letter of January 30 , 1915, and at the same time the promised material. Carrying the investigation a little farther, Professor Moore had brought to light a most unexpected complication. The egg-masses of Mansonia found attached to the under surface of the Pistia leaves were of two kinds, each composed of eggs of a very distinct type, and yet the parents appeared to be alike. In the one kind the thicker or free end of the egg is drawn out into a slender stalk. The other type has a body of similar shape, but the top is drawn out into a short neck like that of a bottle; from the end of this neck project laterally on four sides as

\footnotetext{
${ }^{1}$ We have already pointed out that the eggs figured for this species by Goeldi (Mem. Mus. Goeldi, iv, 1905, pl. I) are those of a species of Aëdes.
} 
many pairs of chitinous horns. We quote from the letter: "There appear to be two types of egg, one terminating in branched spines, the other in a single spine. So far I have had three clusters deposited by confined females and all were of the latter type, none of the branched or antlered type. Both types occur in nature, as you will see from the examples in the tubes, but the single-spined seems to be the less common. Apart from the difference in the spines the eggs seem the same. In tube (5) you will find newly-hatched larvæ from a cluster with the branched spines. They appear to be those of $M$. titillans and have the same habit of sticking their air-tubes into the tissues of the roots, stems and leaves of the Pistia. I shall endeavor to breed out adults from larvæ hatched from these branched-spined egg-masses, although I am certain there is in our canals no other mosquito besides $M$. titillans to which they are referable. I would also have the point settled if a confined female deposits a cluster of this type.

"In the act of hatching the end of the egg bearing the spine or spines breaks off like a cap and allows the young larva to escape. From the submerged position of one of the clusters laid in confinement, as well as of several found in nature, it would appear that $M$. titillans while ovipositing often immerses at least her abdomen in the water."

Professor Moore forwarded two female mosquitoes that had deposited eggs terminating in a single stalk. These proved to be Mansonia titillans beyond question, so that the simpler type of egg was now definitely associated with this species. These eggs may be described as follows:

Length from 1.0 to $1.1 \mathrm{~mm}$.; greatest width, about $0.6 \mathrm{~mm}$. from base, slightly less than $0.2 \mathrm{~mm}$.; beyond this point the egg tapers to a very slender tube, which last takes up about $0.2 \mathrm{~mm}$. of the total length. The attenuation toward the basal end is slightly greater than in eggs of the usual Culex type. The color is the usual pitchy brown, the distal fifth yellowish; the surface is smooth, without perceptible sculpture (Fig. 1).

The egg-mass is rounded and convex, giving the appearance 
of a spiny cushion. The eggs are attached to the leaf with their bases very closely crowded together and apparently held in place by a cement secreted by the female. Owing to their tapering shape, the eggs radiate outward in all directions, the central ones being upright, the outermost ones pressed against the leaf-surface. The number of eggs in a cluster exceeds 150.

The second type of egg, only recently established as belonging to a distinct species described in the following as Mansonia humeralis, is also deposited in a round cushion-like mass, as

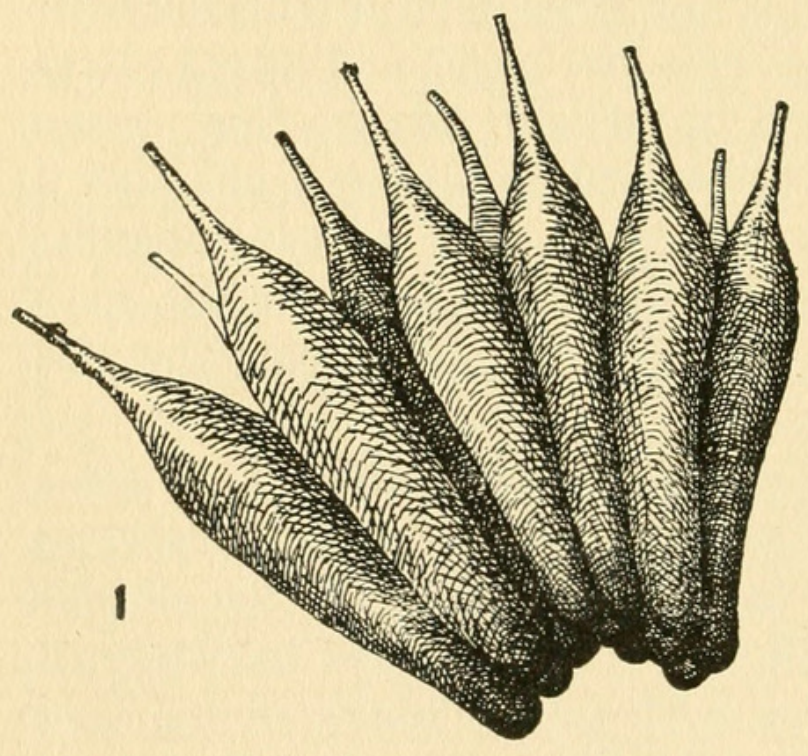

1. Mansonia titillans, small group of eggs.

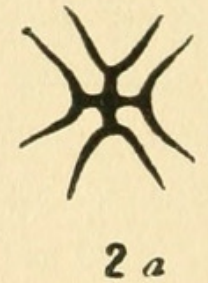

2

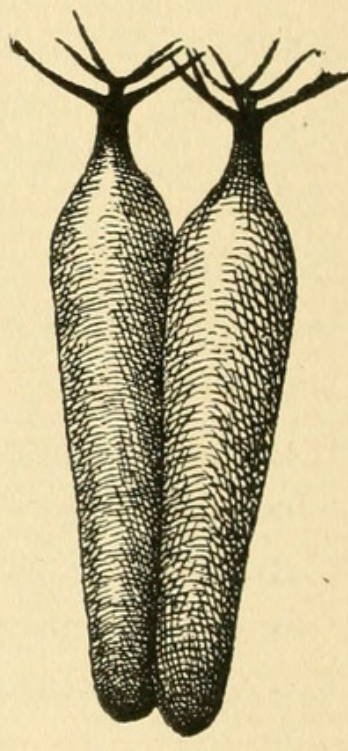

2. Mansonia humeralis, two eggs; $2 a$, top view of terminal spines.

just described for $M$. titillans. The number of eggs appears to be about the same, but the individual eggs are very different and give the mass a very peculiar appearance.

The length of the single egg is about $1.2 \mathrm{~mm}$.; its greatest width is nearer the apex, at about $0.9 \mathrm{~mm}$. from base; beyond this it tapers to a short neck from the upper edge of which project four pairs of horns upon very short stalks; these horns appear to be solid chitin and taper to a sharp point. The distance from tip to tip of opposite horns is from 0.3 to $0.35 \mathrm{~mm}$. The color of the egg is the same as in titillans, but the neck is much darker in color and the horns are black; the egg-surface 
is without perceptible sculpture (Fig. 2). Actual count of the eggs in one cluster gave 182 eggs.

It may be pointed out that in both types of egg the free end, which, owing to the position of the egg-mass projects downward into the water, corresponds to that end of the ordinary Culex egg which is next the water when the egg-raft is afloat. It is the end of the egg which is burst open by the young larva in hatching, which thus gains direct access to its proper medium.

It has been already stated that the spiny type of egg belongs to a distinct species. Professor Moore finally succeeded in establishing this in December, 1915, by confining a female which laid eggs of this type. This female was sent to us and proved to be a species apparently new, described herewith:

Mansonia humeralis, new species.

Female. Occiput deep brown, clothed anteriorly and in a median line with narrow-curved brownish-golden scales, the eye-margins and cheeks with small lanceolate white scales; upright forked scales rather sparse, very slender, black. Proboscis clothed with black and yellowish white scales intermixed, the white scales predominating at middle but not forming a distinct ring; scales roughened on basal half. Palpi over one-fourth the length of the proboscis, clothed with outstanding scales, black and yellowish white ones about evenly intermixed. Antennæ black, the joints with white basal rings; tori brown and black, with a few white scales; second joint with some outstanding white scales.

Mesonotum deep brown, laterally the integument from humeri to near roots of wings broadly yellow-brown, medianly deep brown and with three slightly pruinose depressed longitudinal stripes bounded by the seta-bearing ridges; vestiture of slender curved scales, the yellow-brown side-areas and slightly beyond them to roots of wings, as well as the antescutellar area, clothed rather densely with golden scales, the region above the roots of the wings with a patch of deep brown scales, a few fine golden scales on median zone; bristles coarse, black. Scutellum deep brown, clothed with golden 
scales like those on the mesonotum. Pleuræ light gray-brown, with some small patches of whitish scales. Postnotum deep brown, nude, with a pair of very distinct, ovate pruinose-white spots.

Abdomen depressed, truncate at tip ; dorsal vestiture of dull black scales, the posterior margins of the segments narrowly pale scaled, more broadly so at the angles, second and third segments with an indistinct median triangular patch of dull yellow-brown scales, its base at posterior margin of the segments; first segment sordid white scaled and with many fine yellowish hairs; hairs on the other segments brown; venter clothed with white and black scales intermixed.

Legs clothed with blackish and dull yellowish scales intermixed, the dark ones predominating; front tarsi narrowly marked with white at bases of first three joints, middle tarsi at bases of first four; hind tarsi with white rings at bases of all the joints, narrow on first and second, broad on the others, on the fourth joint occupying the basal half. Claws slender, simple.

Wings hyaline, the venation normal; vestiture of very broad, obliquely subtruncate scales overlying narrower ones, dull black and white intermixed, the black ones predominating. Fringe gray, unspotted. Halteres pale, with blackish knobs.

Length of body, about $6 \mathrm{~mm}$.

Georgetown, British Guiana, December, 1915 (H. W. B. Moore).

Type, Cat. No. 20366, U. S. Nat. Mus.

This species is closely related to Mansonia titillans, but differs strikingly by the three large patches of golden scales upon the mesonotum, as well as in other details. Theobald's $M$. amazonensis and $M$. pseudotitillans are evidently closely related, but apparently distinct. Further collecting will be necessary to establish reliable differences between these three species.

Returning to Mansonia titillans and the question of oviposition, we have an interesting account of the process from Professor Moore, sent under date of April 17, 1915. It is as follows : 
"On March 12, 1915, about 3 p. m., in one of the cane-fields of The Ogle, I was attacked by several M. titillans, of which I secured two. The day before I had also got one at the same estate. On the morning of the 17th one of those captured on the 12 th oviposited between 6.20 and 6.35 , and I was fortunate enough to witness the act. About 6 a. m. I looked through my three glass jars to ascertain if any of the mosquitoes had oviposited, but was unable to see properly, as the light was not yet strong enough. I again examined the glasses at 6.25 , and, not finding one of the mosquitoes, began to think she might be lying dead upon the Pistia or upon the water, whither I then glanced and soon discerned her perched motionless upon a Pistia leaf which was resting upon the surface of the water. But where was her abdomen? Thrust beneath the leaf! In this way was confirmed my surmise that titillans submerges at least her abdomen when ovipositing. Again, how unwonted was her attitude! She was perched, or as it were, between two Pistia leaves, resting upon the one with her fore-legs, and upon the other with her mid and hind legs and also the tips of her wings. Her hind legs were extended well back, so that they practically lay along the surface of the leaf, and her wings were held somewhat apart, this mode of holding legs and wings enabling her to thrust her abdomen well under the leaf. When I first saw her she had deposited only the farther third of her egg-mass. The lower half of her abdomen was submerged and bent or curved back, the segments somewhat extended, and was being moved slowly from side to side, the eggs seeming to issue forth in rapid succession and to be as rapidly set up each in its place. How the terminal organs manipulated the eggs I could not determine, owing to the insect being a little ill-placed for accurate observation in this direction, and to the large number of glistening air-bubbles entangled in the abdominal scales and on the leaf itself. According as the cluster enlarged in her direction, she drew her abdomen more and more up, so that when she finished at 6.35 not much more than the tip of it was curved under the leaf. When she first started more than half of her 
abdomen would have been under the water. The freshly laid cluster was white and the individual eggs of the single-spined type. The surface of the cluster between the spines glowed with air-bubbles. The eggs darkened very slowly.

"I think it is quite possible that when ovipositing the abdomen of titillans, although thrust beneath a leaf resting upon the surface of the water, does not get wet. It is, perhaps, at work in a globule or a layer of air, for, owing to the dense pilosity of the Pistia leaf, the under-surface is simply aglow with air-bubbles, so that the leaf probably rests more on air than on water."

It is interesting to note in this connection that the abdomen of the female Mansonia titillans is unusually hairy, the hairs being well distributed and coarse. This is no doubt an adaptation that by entangling air prevents the body itself from becoming wet while immersed. The remarkable structure of the eggs, and their arrangement, no doubt serves the purpose of keeping them supplied with the necessary air in their submerged position. The difference in the eggs of the two species will be difficult to explain satisfactorily. Professor Moore suggests that the branched horns of the one type may be a protection against enemies. We are inclined to think that it is connected in some way with the problem of air-supply, the eggs of the two species perhaps being deposited in slightly different relation to the water.

Finally should be noted the fact brought out by Professor Moore's notes that in Mansonia titillans there is a very definite relation between blood-meals and oviposition. In four cases noted oviposition followed the blood-meal after an interval of from four to five days. One female laid two batches of eggs; she was fed on January 15 and oviposited on the night of the 19 th ; fed again on the 20th, she laid a second cluster on the 25th and died two days later. 


\section{$2 \mathrm{BHL}$ Biodiversity Heritage Library}

1916. "Eggs and oviposition in certain species of Mansonia." Insecutor inscitiae menstruus 4, 61-68. https://doi.org/10.5962/bhl.part.8950.

View This Item Online: https://www.biodiversitylibrary.org/item/34104

DOI: https://doi.org/10.5962/bhl.part.8950

Permalink: $\underline{\text { https://www.biodiversitylibrary.org/partpdf/8950 }}$

\section{Holding Institution}

Smithsonian Libraries

\section{Sponsored by}

Smithsonian

\section{Copyright \& Reuse}

Copyright Status: NOT_IN_COPYRIGHT

This document was created from content at the Biodiversity Heritage Library, the world's largest open access digital library for biodiversity literature and archives. Visit BHL at https://www.biodiversitylibrary.org. 